\title{
Depression and Exercise: A Clinical Review and Management Guideline
}

\author{
Elaheh Ranjbar ${ }^{1}$; Amir Hossein Memari ${ }^{1,}$; Sina Hafizi ${ }^{1}$; Monir Shayestehfar ${ }^{2}$; Fatemeh \\ Sadat Mirfazeli ${ }^{1}$; Mohammad Ali Eshghi ${ }^{3}$ \\ ${ }^{1}$ Sports Medicine Research Center, Neuroscience Institute, Tehran University of Medical Sciences, Tehran, IR Iran \\ ${ }^{2}$ Shahid Beheshti University of Medical Sciences, Tehran, IR Iran \\ 3 Exercise Physiology Research Center, Baqiyatallah University of Medical Sciences, Tehran, IR Iran \\ ${ }^{*}$ Corresponding author: Amir Hossein Memari, Sports Medicine Research Center, Neuroscience Institute, Tehran University of Medical Sciences, Tehran, IR Iran. Tel: +98-2188330032, \\ E-mail:amirmemari@farabi.tums.ac.ir
}

Received: October 1, 2014; Accepted: November 17, 2014

\begin{abstract}
Context: There is an increasing interest to detect how exercise affects depression symptoms. Although recent findings confirm the positive effect of exercise on depression, there is no clear guideline regarding advice on exercise for patients with depression. The following review aims at presenting the contemporary literature regarding the nature of depression, exercise, the underlying mechanisms, and the management of an exercise program in individuals with depression.

Evidence Acquisition:We searched electronic databases including Cochrane Library, PubMed, ISI web of knowledge, and PsychInfo (from January 2000 to October 2014). We reviewed the systematic reviews, meta-analyses, and large-scale randomized control trials on effects of exercise on depression.

Results: Recent evidence has emerged on characteristics of effective exercise programs and those patients with depression that will most benefit from the exercise programs. However, due to the methodological weaknesses and inconsistencies of studies, conclusions must be made with caution.

Conclusions: We have provided a number of recommendations for clinicians and researchers who plan to use exercise protocols in depression.
\end{abstract}

Keywords: Depression; Exercise; Brain; Physical Activity; Depressive Symptoms; Antidepressant Effect

\section{Context}

Increasing incidence of depression with almost 340 million people that have been involved worldwide places a huge burden on our health. In this way, depression will be the second cause of mortality and morbidity, only after heart disease in 2020 (1). Diagnostic and Statistical Manual of Mental Disorders places greater emphasis on depressive mood or loss of interest as the main symptoms of depression (2). However, findings show that depression is often accompanied by other problems such as low level of physical activity (3). Furthermore, a lot of research has been done to assess how physical activity (e.g. exercise) and depression influence each other (4-6). Indeed, the large effect sizes especially in clinically depressed samples indicate that exercise is an effective treatment for major depressive disorder (MDD) (7). The main results from several meta-analyses show that exercise has an antidepressant effect compared with control conditions that ranges from slightly moderate to very large $(8,9)$. Although some studies indicate that exercise does not differ from traditional treatment (antidepressant medication or psychotherapy) in reducing depression symptoms (10), exercise combined with psychotherapy appears to produce even better results than either by itself (11). Moreover, exercise training is inexpensive and there is no stigma attached to exercise $(12,13)$. In other words, exercise is safe and has no side effects, thus it is more reliable than medications particularly for some patients such as pregnant women and children $(14,15)$. Deslandes et al. reported that clinically depressed patients could significantly reduce the dose of medication when they exercised $(16,17)$. Furthermore, in a 6 month follow-up study, Babyak et al. (18) showed that depressed patients, assigned to the aerobic training program, were less likely to relapse than patients who were assigned to receive medication treatment. Many people with depression express frustration about the usual care, citing reasons such as inadequate symptom management, unacceptable side effects, and inadequate methods for coping (19). Data shows that negative attitudes to psychotherapy have led to increased interest in alternative treatment options for depression. Keeping in mind that exercise shows no medication side effects such as withdrawal symptoms (20), weight gain, dry mouth, or insomnia (21), but shows potential health benefits, such as weight reduction, it is highly recommended to use ex-

Copyright (C) 2015, Sports Medicine Research Center. This is an open-access article distributed under the terms of the Creative Commons Attribution-NonCommercial 4.0 International License (http://creativecommons.org/licenses/by-nc/4.0/) which permits copy and redistribute the material just in noncommercial usages, provided the original work is properly cited. 
ercise as an adjunctive treatment for depression (22). New findings confirm that exercise can be recommended as a first-line treatment for mild to moderate depression; as an adjunct to medications (23); as an alternative to cognitive behavioral therapy (11); and in preventing depression in clinical as well as healthy populations (24-26). However, many questions are still open. For instance, it is not clear what type of exercise can cover a wide range of patients with depression. We aimed to present the current state of knowledge on the nature of the relationship between exercise and depression and present the current state of art in management of an exercise program for individuals with depression.

\section{Evidence Acquisition}

We reviewed papers published from January 2000 to October 2014, consulting the following databases: Cochrane Library, PubMed, ISI web of knowledge, and PsychInfo. We developed a search strategy for each electronic database using the combination of word terms: depression, major depression, depressive symptoms, physical activity, exercise, intervention, treatment, and antidepressant effects. We also manually searched reference lists of selected papers for further relevant publications. Finally we reviewed the scientific articles included systematic reviews, metaanalyses and large-scale randomized control studies examining the efficacy of exercise treatments for depression.

\section{Results}

\subsection{Patients' Characteristics}

Before deciding to advise exercise as a treatment for individuals with depression, it is recommended to monitor the important variables and enroll eligible patients in intervention programs. Sociodemographics (e.g. age, sex, race/ethnicity, marital status, and occupation), body mass index (BMI), level of disability, family history of depression, level of physical activity, genetic, and personality factors can influence the extent to which physical activity and depressive symptoms are related on an individual basis. General health indices should also be considered at initial assessment sessions (27). Furthermore, patients' perceptions and views about therapy; history of recent major stressful life events (28), mobility status and the need of assistive device, and available facilities and instruments should be considered during patient enrollment. It is also important to ensure that adequate supervision and follow up services are available (29). However, presence of the following items may decrease the success rate of exercise treatment: suicidal tendency, psychosis, mania, medical conditions making exercise difficult, hospitalization or surgery in the past month and changes in antidepressant medication dosing over the past month (30). Existing theories and models indicate how biological, psychosocial, and environmental factors mediate the effect of exercise on depression (Figures 1 and 2) (31). For example, when considering socioeconomic class and educational level, people with higher education levels and income status may have more information about treatment options and the likelihood of success in relieving depression than those with lower levels (32). Family history of depression is a proxy for genetics, which modifies the relation between physical activity and depressive symptoms (33). It is also important to consider gender differences in designing exercise programs since women report more depressive symptoms and less frequently involve in physical activity than men (34). Indeed exercise can be recommended for people with depressive disorders within every demographic group independent of their socioeconomic status, though a stronger effect has been indicated in women, people over age 40 , and individuals with obesity or disability $(32,35)$ (see Box 1). Keeping in mind different types of depression (MDD, mild depression, non-clinical population with depressive symptoms), exercise can be recommended depending on individual needs and preferences. Meta-analysis studies indicate that clinical patients with moderate to severe depression who did exercises, report greater reductions in depressive symptoms than other patients. Some authors are still concerned about compliance of depressive patients with their exercise program; though others believe that even patients with MDD are able to complete an exercise program similar to healthy controls $(7,36)$. Studying other types of depression has been of recent interest in the literature (Box 2). For example, findings have clearly illustrated that exercise during pregnancy benefits mental and physical health of the mother and fetus with low chance of injury (37). It is also shown that exercise can be effective as an adjunctive treatment for postnatal depression though many aspects of this interaction remain provisional and require confirmation (38).

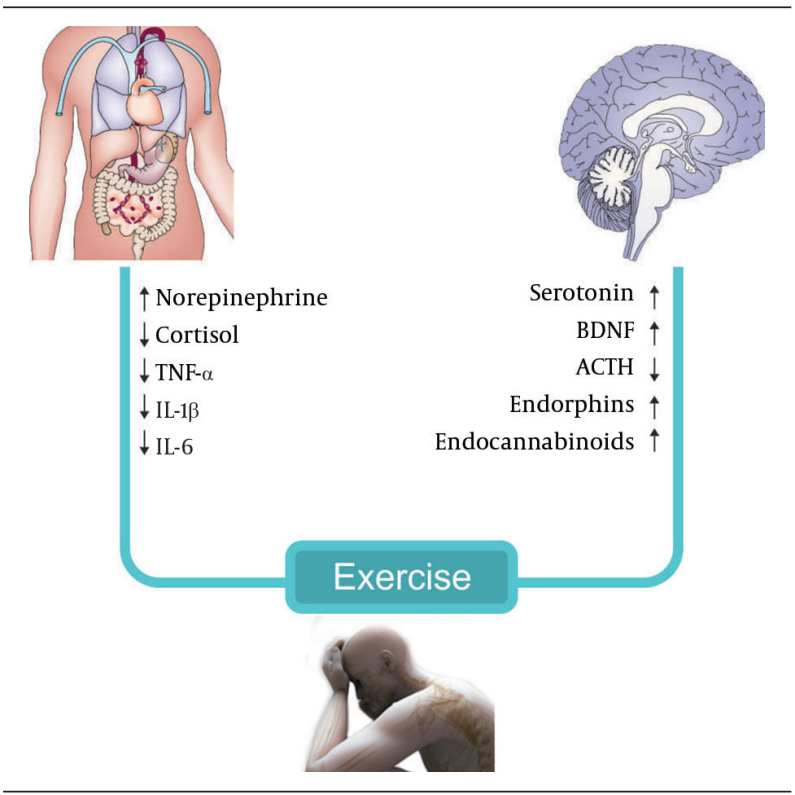

Figure 1. Biological Effects of Exercise on Patients with Depression 
RanjbarE et al.

\subsection{Exercise Characteristics}

After a long discussion on the question about type of exercise, it seems that both aerobic (e.g. running, swimming) and anaerobic (e.g. resistance training) exercises are effective in decreasing depression symptoms and enhancing positive mood in patients (11).

However, there are a few difficulties related to resistance training interventions. They need more physical space, financial investment and qualified supervision. This may suggest the aerobic exercise as an easier option to employ (39). For example, walking as an aerobic exercise may be a cost-effective option for the treatment of depression though stationary cycles or treadmill are alternatives (40, 41). Surprisingly, recent data show that increasing lifestyle physical activities (e.g. occupational, recreational, household, and transportation) may also help to decrease depressive symptoms (42). Another important question is whether group or individual exercise programs influence depression outcomes equally (43). There are many benefits achieved via group exercise, as enhancing the perception of enjoyment, feeling of belonging in a social context and social support (44). Group exercises are recommended specially for women, adolescents, people under stressful conditions and chronically ill people (45). It seems that opportunities available through the group exercises, such as connectedness, sharing experiences, social skills training, and motivating and encouraging atmosphere can help to decrease depressive symptoms (10). On the other hand, a few people may prefer to join individual exercise programs. Studies indicated the value of individual work out sessions in skill training, and also a realistic goal setting due to the patient ability. The individual exercise sessions have an additive effect on improving participant compliance for treatment program (46). Another strategy is the use of supervised exercise programs. A few studies support that supervised exercise may help to enhance adherence to intervention programs though there are many aspects which remain to be elucidated (11). However, still the decision of how constantly to pursue each strategy (e.g. group program, supervised exercise) rests on the judgment of the investigator or practitioner (BOX 3). There are too many controversies about the best intensity of exercise program to improve depressive symptoms. For example, it has been shown that there is no significant difference between a high intensity aerobic exercise $\left(65-75 \% \mathrm{VO}_{2}\right.$ max reserve), low intensity aerobic exercise (40-55\% $\mathrm{VO}_{2}$ max reserve), or a stretching program in the reduction of depressive symptoms (46). Regarding exercise duration, there is no significant difference between training 3 and 5 days/ week. Furthermore, similar to the recommendations from the American College of Sports Medicine, an energy expenditure of $17 \mathrm{kcal} / \mathrm{kg} /$ week or at least $150 \mathrm{~min} /$ week will be the best practice for treatment of patients with depression (47). Considering all factors, it is recommended that moderate-intensity training (70\% of one-repetition maximum) and 30 minutes on most, if not all days of the week in adults and twice a week in elderly subjects is the best condition to achieve immediate, large, and enduring antidepressant effects . Also it is recommended that the positive effects of exercise are larger when continued at least 10 weeks and, preferably, greater than 15 weeks (Box 3). As a caution, there is no linear correlation between intensity of exercise and its positive effects since too high-intensity exercise may create hatred toward it and have negative consequences (48). Another important implication for practitioners is that the context of physical activity (e.g. where, when, and with whom) may be more important than the absolute intensity, duration and frequency of exercise. The success rate of exercise therapy is also associated with adherence to the exercise program. As a strategy to retain subjects in the exercise group, using music or games and including enjoyable, preferred, and recreational activities are helpful (49). Also, behavioral techniques (e.g. class handouts, daily logs) may facilitate adherence to the home exercise programs (50). For example, the daily exercise logs can play a key motivator for regular practice during the intervention period and help to develop appropriate goals, achieve self-regulation, and adhere to interventions (51). Further, communication modalities including telephone interviews, consultations, texting, leaflets, and use of word-of-mouth could also be implemented by intervention team (27).

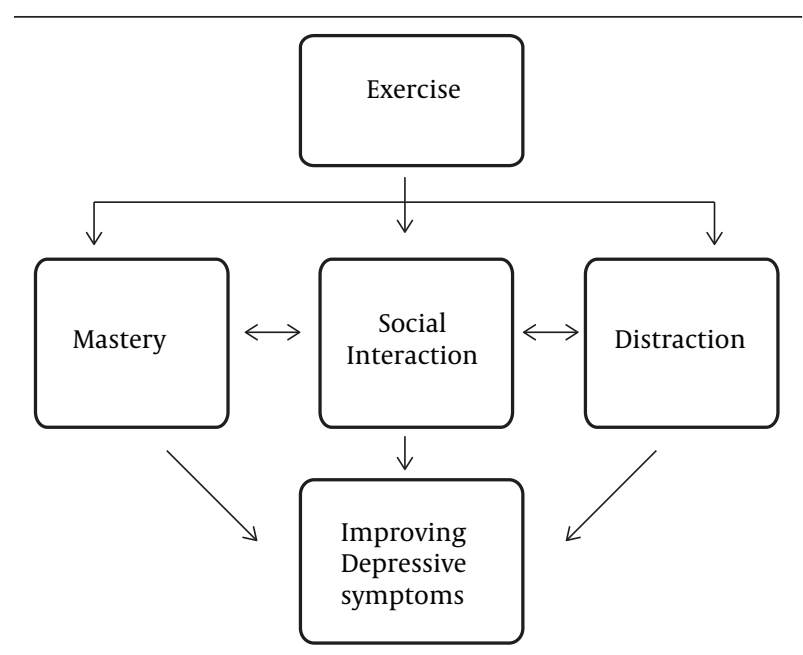

Figure 2. Psychosocial Effects of Exercise on Patients With Depression

Box 1. Patients With Depression Who May Particularly Benefit From Exercise Programs

\begin{tabular}{l}
\hline Patients Characteristics \\
\hline$\leq 20$ or $\geq 40$ years old \\
Higher educational status \\
Higher physical status \\
Females rather than males \\
Untrained patients \\
Those with mild to moderate depression \\
\hline
\end{tabular}


RanjbarE et al.

\begin{tabular}{|c|c|}
\hline Types of Depression & Definition \\
\hline Dysthymia & Dysthymia is a mild but long-term form of depression. Symptoms usually last for at least two years. \\
\hline Atypical depression & $\begin{array}{l}\text { This type involves only some of the symptoms of major depression. Common symptoms of atypical de- } \\
\text { pression include increased appetite or weight gain, sleepiness, or excessive sleep, and feeling extremely } \\
\text { sensitive to rejection. }\end{array}$ \\
\hline Seasonal depression & $\begin{array}{l}\text { Seasonal depression, also known as winter depression or blues, summer depression or blues, was } \\
\text { considered a mood disorder in which people who have normal mental health throughout most of the } \\
\text { year, experience depressive symptoms in the winter or summer. }\end{array}$ \\
\hline Bipolar depression & $\begin{array}{l}\text { Bipolar disorder (manic-depressive disorder) is diagnosed in individuals experiencing episodes of a } \\
\text { frenzied mood known as mania, typically alternating with episodes of depression. }\end{array}$ \\
\hline Postnatal depression & $\begin{array}{l}\text { Postnatal depression or postpartum depression is a type of clinical depression which can affect women, } \\
\text { and less frequently men, typically after childbirth. It usually develops in the first four to six weeks after } \\
\text { childbirth, even may develop after several months. However, many women are not aware they have the } \\
\text { condition. Common symptoms are low mood, feeling unable to cope, and difficulty sleeping. }\end{array}$ \\
\hline $\begin{array}{l}\text { Premenstrual } \\
\text { syndrome }\end{array}$ & $\begin{array}{c}\text { Premenstrual syndrome is a collection of emotional symptoms, with or without physical symptoms, } \\
\text { related to a woman's menstrual cycle. }\end{array}$ \\
\hline
\end{tabular}

Box 3. The Characteristics of an Exercise Program That Will Maximize the Anti-Depressive Properties ${ }^{\text {a }}$

\begin{tabular}{l}
\hline Exercise Characteristics \\
\hline Structured exercise (SIGN and NICE) \\
$\begin{array}{l}\text { Aerobic exercise (e.g. cycling), resistance exercise (e.g. } \\
\text { weight lifting ) or mixed exercise }\end{array}$ \\
Supervised exercise (SIGN and NICE) \\
$\begin{array}{l}\text { Low to moderate intensity (regarding patient } \\
\text { preference) }\end{array}$ \\
$\mathbf{4 5}$ min to 1 h/ session (NICE) \\
\hline At least three to four times weekly, $\geq \mathbf{1 5 0}$ min/week \\
\hline Course duration $\geq \mathbf{1 0}$ weeks (NICE) \\
Individually tailored exercise \\
Exercise as an adjunct therapy to medication \\
\hline a Abbreviations: NICE, National Institute for Health and Care \\
Excellence; SIGN, Scottish Intercollegiate Guidelines Network.
\end{tabular}

\subsection{A Multidisciplinary Approach}

It is very beneficial to encourage physicians and exercise specialists to work in collaboration on depression and exercise treatments. It seems that most medical professionals have little or no training in exercise programs and exercise specialists are not familiar with the clinical population particularly depressed patients. Physicians' recommendation is often limited to "get more exercise" while the exercise specialist may advise physical activities that are not actually useful for patients with depression. However, with a multidisciplinary team, it is possible to prescribe an exercise program more safely, efficiently, operatively, objectively, and realistic (52). Such a multidisciplinary team may include a psychiatrist or clinical psychologist, sports medicine specialist and exercise trainer.

\section{Discussion}

Although recent findings have shown that exercise can decrease depressive symptoms, there are still many questions and limitations to wider application of exercise in depression. For instance, there are deficiencies in methodological planning such as uncontrolled nonrandomized trials, small sample sizes, inadequate allocation concealment, lack of intention-to-treat analyses, non-blinded outcome assessments, and inclusion of subjects without clinical diagnosis that limit the interpretability of research outcomes (53). It has not appeared as yet which type of control group (waiting list, usual care, or placebo) is the most suitable group to compare the experimental group with. Another important question is to what extent and how long the exercise programs will influence the depression or depressive symptoms.

Furthermore, the effects of sedentary state rather than exercise behaviour on the relationship between exercise and depression have not been explored yet. There are insufficient data to support or refute exercise for treating less common types of depression such as postpartum blues, seasonal, bipolar depression, depression with chronic diseases, and premenstrual depressive symptoms (11). There are still many questions on biological effects of exercise training on depression. Although exercise can cause the brain and behavioral changes, and several hypotheses link them together, we are not certain about these behavioral changes and corresponding changes in brain and neuroendocrine. Consequently, to address these questions, a number of recommendations have been provided in Box 4 for researchers who plan to use exercise protocols in depression. To date, therapeutic effects of exercise on depression have been documented. Choosing the right exercise for the right person besides long-term follow up can help to ensure the exercise interventions are having the intended effects. Future research needs refined models, methodological convergence, and stronger biological links. 
Box 4. Recommendations for Future Trials of Exercise Interventions for Depression

\begin{tabular}{l}
\hline Well-Designed Studies Must \\
\hline Be randomized \\
Be controlled \\
\hline Include blinded outcome measurement \\
\hline Include appropriate sample size \\
\hline Include adequate allocation concealment \\
\hline Include clear inclusion/ exclusion criteria \\
\hline Match the definition and assessment of depression \\
\hline Determine dropout rates and its reasons \\
\hline Consider both quality and quantity characteristics of \\
exercise \\
\hline Use waiting list control condition \\
\hline Consider cultural, moral and demographic factors \\
effects \\
\hline Determine co-interventions (e.g. medication effects) \\
\hline Consider in-task and post exercise affective responses \\
\hline Include biological variables (e.g. neurohormonal, \\
neuroimaging variables) \\
\hline Measure sedentary behaviors in addition to physical \\
activity \\
\hline Consider long term follow up \\
\hline Do sensitivity analyses to show the accurate effect size \\
\hline Include intention- to-treat analysis \\
\hline Consider cost- effectiveness of different types of exercise \\
\hline Report all relevant and irrelevant outcomes \\
\hline Publish trials with negative outcomes \\
\hline
\end{tabular}

\section{References}

1. Chapman DP, Perry GS. Depression as a major component of public health for older adults. Prev Chronic Dis. 2008;5(1):A22.

2. American Psychiatric Association.. Diagnostic and Statistical Manual of Mental Disorders.Washington DC: American Psychiatric Press; 2000.

3. Strohle A. Physical activity, exercise, depression and anxiety disorders. J Neural Transm. 2009;116(6):777-84.

4. Memari AH, Kordi R, Panahi N, Nikookar LR, Abdollahi M, Akbarnejad A. Effect of ramadan fasting on body composition and physical performance in female athletes. Asian J Sports Med. 2011;2(3):161-6.

5. Seif-Barghi T, Kordi R, Memari AH, Mansournia MA, Jalali-Ghomi $M$. The effect of an ecological imagery program on soccer performance of elite players. Asian J Sports Med. 2012;3(2):81-9.

6. Kordi R, Abdollahi M, Memari AH, Najafabadi MG. Investigating Two Different Training Time Frames during Ramadan Fasting. Asian J Sports Med. 2011;2(3):205-10.

7. Rethorst CD, Wipfli BM, Landers DM. The antidepressive effects of exercise: a meta-analysis of randomized trials. Sports Med. 2009;39(6):491-511.

8. Krogh J, Nordentoft M, Sterne JA, Lawlor DA. The effect of exercise in clinically depressed adults: systematic review and meta-analysis of randomized controlled trials. J Clin Psychiatry. 2011;72(4):529-38.
9. Stathopoulou G, Powers MB, Berry AC, Smits JAJ, Otto MW. Exercise Interventions for Mental Health: A Quantitative and Qualitative Review. Clin Psychol Sci Prac. 2006;13(2):179-93.

10. Mead GE, Morley W, Campbell P, Greig CA, McMurdo M, Lawlor DA. Exercise for depression. Cochrane Libr. 2009.

11. Rimer J, Dwan K, Lawlor DA, Greig CA, McMurdo M, Morley W, et al. Exercise for depression. Cochrane Database Syst Rev. 2012;11.

12. Memari AH, Ghanouni P, Shayestehfar M, Ziaee V, Moshayedi P. Effects of visual search vs. auditory tasks on postural control in children with autism spectrum disorder. Gait Posture. 2014;39(1):229-34.

13. Memari AH, Ghaheri B, Ziaee V, Kordi R, Hafizi S, Moshayedi P. Physical activity in children and adolescents with autism assessed by triaxial accelerometry. Pediatr Obes. 2013;8(2):150-8.

14. Memari AH, Ziaee V, Beygi S, Moshayedi P, Mirfazeli FS. Overuse of psychotropic medications among children and adolescents with autism spectrum disorders: perspective from a developing country. Res Dev Disabil. 2012;33(2):563-9.

15. Memari AH, Ghanouni P, Gharibzadeh S, Eghlidi J, Ziaee V, Moshayedi P. Postural sway patterns in children with autism spectrum disorder compared with typically developing children. Res Autism Spectrum Disord . 2013;7(2):325-32.

16. Deslandes A, Moraes H, Ferreira C, Veiga H, Silveira H, Mouta R, et al. Exercise and mental health: many reasons to move. Neuropsychobiology. 2009;59(4):191-8.

17. Laurin D, Verreault R, Lindsay J, MacPherson K, Rockwood K. Physical activity and risk of cognitive impairment and dementia in elderly persons. Arch Neurol. 2001;58(3):498-504.

18. Babyak M, Blumenthal JA, Herman S, Khatri P, Doraiswamy M, Moore K, et al. Exercise treatment for major depression: maintenance of therapeutic benefit at 10 months. Psychosom Med. 2000;62(5):633-8.

19. Lafrance MN. Constructing a Non-depressed Self: Women's Accounts of Recovery from Depression. Feminism \& Psychology. 2006;16(3):307-25.

20. Ebmeier KP, Donaghey C, Steele JD. Recent developments and current controversies in depression. Lancet. 2006;367(9505):153-67.

21. Trindade E, Menon D, Topfer LA, Coloma C. Adverse effects associated with selective serotonin reuptake inhibitors and tricyclic antidepressants: a meta-analysis. CMAJ. 1998;159(10):1245-52.

22. Daley A. Exercise and depression: a review of reviews. J Clin Psychol Med Settings. 2008;15(2):140-7.

23. Carek PJ, Laibstain SE, Carek SM. Exercise for the treatment of depression and anxiety. Int J Psychiatry Med . 2011;41:15-28.

24. O'Neal HA, Dunn AL, Martinsen EW. Depression and exercise. Int J Sport Psychol. 2000;31(2):110-35.

25. Ryan MP. Psychocultural differences in physical activity-based antidepressant effects. Ment Health Phys Act. 2010;3(1):5-15.

26. Peluso MA, Guerra DE, Andrade LH. The association between exercise and mood. Phys Ment Health . 2005.

27. Evenson KR, Wen F. Measuring physical activity among pregnant women using a structured one-week recall questionnaire: evidence for validity and reliability. Int J Behav Nutr Phys Act. 2010;7:21.

28. Kendler KS, Thornton LM, Gardner CO. Stressful life events and previous episodes in the etiology of major depression in women: an evaluation of the "kindling" hypothesis. Am J Psychiatry. 2000;157(8):1243-51.

29. Rosenberg DE, Bombardier CH, Artherholt S, Jensen MP, Motl RW. Self-reported depression and physical activity in adults with mobility impairments. Arch Phys Med Rehabil. 2013;94(4):731-6.

30. Kinser PA, Bourguignon C, Whaley D, Hauenstein E, Taylor AG. Feasibility, acceptability, and effects of gentle Hatha yoga for women with major depression: findings from a randomized controlled mixed-methods study. Arch Psychiatr Nurs. 2013;27(3):137-47.

31. Memari AH, Ziaee V, Shayestehfar M, Ghanouni P, Mansournia MA, Moshayedi P. Cognitive flexibility impairments in children with autism spectrum disorders: links to age, gender and child outcomes. Res Dev Disabil. 2013;34(10):3218-25.

32. NationalCenter for Health Statistics.. Health, United States 2011 With Special Feature on Socioeconomic Status and Health.Washington DC: National Center for Health Statistics; 2011. 
33. Mata J, Thompson RJ, Gotlib IH. BDNF genotype moderates the relation between physical activity and depressive symptoms. Health Psychol. 2010;29(2):130-3.

34. Torres ER, Sampselle CM, Gretebeck KA, Ronis DL, Neighbors HW. Physical activity effects on depressive symptoms in Black adults. J Health Dispar Res Pract. 2010;4(2):70.

35. Wise LA, Adams-Campbell LL, Palmer JR, Rosenberg L. Leisure time physical activity in relation to depressive symptoms in the Black Women's Health Study. Ann Behav Med. 2006;32(1):68-76.

36. Arent S, Landers D, Etnier J. The effects of exercise on mood in older adults: A meta-analytic review. J Aging Phys Act. 2000;8(4):407-30.

37. U.S. Department of Health and Human Services.. Physical Activity Guidelines for Americans.USA: Bethesda; 2008.

38. Daley AJ, Jolly K, Sharp DJ, Turner KM, Blamey RV, Coleman S, et al The effectiveness of exercise as a treatment for postnatal depression: study protocol. BMC Pregnancy Childbirth. 2012;12:45.

39. National Institute for Health and Care Excellence.. Depression in adults: The treatment and management of depression in adults.: NICE; 2009.

40. Robertson R, Robertson A, Jepson R, Maxwell M. Walking for depression or depressive symptoms: a systematic review and metaanalysis. Ment Health Phys Act. 2012;5(1):66-75.

41. Trivedi MH, Greer TL, Church TS, Carmody TJ, Grannemann BD, Galper DI, et al. Exercise as an augmentation treatment for nonremitted major depressive disorder: a randomized, parallel dose comparison. J Clin Psychiatry. 2011;72(5):677-84

42. Mead GE, Morley W, Campbell P, Greig CA, McMurdo M, Lawlor DA. Exercise for depression. Cochrane Database Syst Rev. 2009(3):CD004366.

43. Mota-Pereira J, Silverio J, Carvalho S, Ribeiro JC, Fonte D, Ramos J. Moderate exercise improves depression parameters in treatment-resistant patients with major depressive disorder.J Psychi- atr Res. 2011;45(8):1005-11.

44. Gore S, Farrell F, Gordon J. Sports Involvement as Protection against Depressed Mood. J Res Adolesc. 2001;11(1):119-30.

45. Luyten P, Blatt SJ, Van Houdenhove B, Corveleyn J. Depression research and treatment: are we skating to where the puck is going to be? Clin Psychol Rev. 2006;26(8):985-99.

46. Chu IH, Buckworth J, Kirby TE, Emery CF. Effect of exercise intensity on depressive symptoms in women. Men Health Phys Act. 2009;2(1):37-43.

47. Dunn AL, Trivedi MH, Kampert JB, Clark CG, Chambliss HO. Exercise treatment for depression: efficacy and dose response. Am J Prev Med. 2005;28(1):1-8.

48. Stanton R, Reaburn P. Exercise and the treatment of depression: a review of the exercise program variables. J Sci Med Sport. 2014;17(2):177-82.

49. Cotter KA, Lachman ME. No strain, no gain: psychosocial predictors of physical activity across the adult lifespan.J Phys Act Health. 2010;7(5):584-94.

50. Whaley DE. Seeing isn't always believing: Self-perceptions and physical activity behaviors in adults. In: Weiss MR editor. Developmental sport and exercise psychology: A lifespan perspective.. Morgantown WV: Fitness Information Technology; 2004.

51. Vealey RS. Mental skills training in sport. In: Tenenbaum G, Eklund RC editors. Handbook of sport psychology.. Hoboken NJ: ohn Wiley \& Sons; 2007.

52. American College of Sports Medicine.. ACSM's guidelines for exercise testing and prescription. 6th edPhiladelphia Pennsylvania: Lippincott Williams \& Wilkins; 2000.

53. Lawlor DA, Hopker SW. The effectiveness of exercise as an intervention in the management of depression: systematic review and meta-regression analysis of randomised controlled trials. BMJ. 2001;322(7289):763-7. 